\title{
谈基层烟叶生产管理存在的问题及对策
}

\author{
柏雪 \\ 南丹县烟叶产业发展中心 \\ DOI:10.32629/as.v3i3.1839
}

\begin{abstract}
[摘 要] 为保证基层烟叶生产质量,提高企业经济效益,做好基层烟叶生产管理是非常必要的。不过从对 目前基层烟叶生产管理的研究可知,其还存在着诸多不足,如技术水平和专业化管理能力较低、机械化作 业效率低、工作人员积极性较弱等,这些问题的出现对基层烟叶企业的前行带来了阻碍。基于此,应针对 现存问题提出合理的解决措施,以提高基层烟叶生产管理水平,推动产业的稳定发展。
\end{abstract}

[关键词] 基层烟叶生产管理; 解决措施; 稳定发展

中图分类号：F768.29 文献标识码：A

目前, 烟草农业的现代化改革日渐 深入, 但因受到传统理念、方式方法的影 响, 烟草农业在发展中面临着诸多问题, 需要加大研究和探讨力度, 以巩固企业 的经济实力。在烟草农业发展中, 需要从 生产力、政策措施、人员能力素质、环 境等多方面展开综合分析, 合理规划生 产管理内容, 改进机械化作业效率, 为我 国农业建设贡献力量。

\section{1 基层烟草生产管理中存在的} 问题

1. 1技术水平不高, 无法实现专业化 管理

烟草作为可塑性较强的经济作物, 生产技术会直接决定烟草生产质量。随 着城市化建设速度的加快, 农村年轻劳 动力大量涌入城镇, 只留有少量能力不 高人群或老年人居于农村, 这些人要么 自身知识水平较低, 要么身体素质较差, 在烟草生产中, 难以做到对先进技术的 把控, 烟草生产技术水平不足, 生产质量 难以保障。

\section{2 种植积极性较差}

农业产业结构的调整不仅会对自身 发展带来助力, 也为相关产业建设提供 了帮助, 农资、人工、农产品的价格均得 到一定提升, 但对于烟草种植来说, 由于 我国对其并未有详细的政策说明, 烟草 收购的价格并未有所上涨, 这在农资、人 工等上涨的条件下, 无疑会加重烟草种
植的压力, 再加上烟草种植中受自然灾 害及病虫害的影响较为明显, 带来的损 失较大, 导致很多农户放弃烟草种植工 作, 选择其他成本低廉, 经济效益好的农 作物加以种植, 致使烟草生产面临较大 困难。另外, 目前针对烟草的风险承担机 制还不完善, 在面临自然灾害或病虫害 时, 没有科学有效的保障机制, 农民多数 不愿意承担风险事项, 种植积极性越来 越低。

1. 3基础设施配备不完善, 机械化水 平低

烟草生产是一项较为复杂的工作, 对技术、人员、环境等均有着较高要求, 虽然一些地方通过烟水工程、烟基工程 的建设改善烟草种植和生产中存在的问 题, 营造良好的生产环境, 但仍有较大部 分地区在烟草生产中还在采用人工种植 方式, 所有工作全部依靠人力加以完成, 机械设备设施缺失严重, 机械化作业效 率较低。另外, 随着城市化进程的加快, 基层烟草种植面临着严重的人力不足局 面, 如果不能改进机械化作业效率, 烟草 产量和质量会快速下降, 不利于我国烟 草农业的发展。

1. 4 基层烟草生产管理水平不高

新形势下, 各领域均得到了创新和 优化, 基层烟草产业要想在新形势下站 稳脚跟, 以现代化管理理念落实烟草生 产管理是必然的。但目前很多企业并未
注意到这一特征, 在基层烟草生产管理 中, 仍在沿用传统的管理理念和方式, 生 产管理模式单一、产品质量得不到保障。 基层烟草站直接面对烟农,一定要做到 以服务烟农为导向, 在正常业务范围内, 开展技术服务、经营服务、管理服务, 最大限度地为烟农服务, 指导烟农运用 现代科学技术, 切实提高烟农经济效益, 发挥出基层烟草站的技术指导作用。

\section{2 基层烟草生产管理的对策和} 建议

若想更好的提高基层烟草生产管理 工作的质量, 就需要在对问题进行全面 分析的基础上, 采取有针对性的解决对 策, 具体而言, 笔者认为可以从如下几个 方面着手:

2.1落实标准化、规范化生产要求

基层烟叶生产中, 应坚持服务客户 的基本理念, 从烟农自身角度出发, 为其 提供专业培训和指导, 改善烟草生产水 平。优化传统烟叶生产模式, 融入现代化 管理理念, 达到标准化、规范化生产目 标。这样一方面是为了保护烟草生产质 量, 提高产量, 降低病虫害及自然灾害威 胁, 一方面也是为农户自身经济效益着 想, 增加其经济收入。烟叶生产标准化集 先进科技成果和现代管理技术于一体, 力求用现代工业理念来指导烟叶生产, 用现代科学技术来改造传统生产方式, 用现代标准来规范烟叶生产和经营管 
理。可以说, 实施标准化生产是实现烟叶 生产现代化的必经之路。

2. 2 配备齐全的设备设施, 提高机械 化作业效率

结合目前烟草生产存在的问题, 应 针对烟草种植区域的实际情况, 加大基 础设施配备力度, 改善机械化作业水平。 同时做好种植户的管理和培训, 使其了 解机械作业生产带来的优势作用, 加大 对机械作业的认知, 合理应用先进技术 和机械, 达到企业管理和发展目标。再者, 还应加大烟水工程、烟基工程的建设力 度, 为烟草生产提供良好条件。且机械化 水平的提高也可降低人力上的损耗, 这 对于解决劳动力供应不足问题, 降低人 工成本有着积极意义。

2.3 基层烟草的规模化和专业化 种植

基层烟草的规模化、专业化生产是 提高烟草质量和产量的基础与前提, 也 是烟草产业现代化发展的基础。在基层 烟草规模化、专业化种植中, 需针对种植 户的实际情况采取不同的规划、管理方 式: 针对现阶段存在的小规模的烟草种 植户, 坚持专业化、规模化的发展要求, 根据自身条件和优势, 不断尝试改革和 创新, 以加强烟草种植效果, 促进烟草农 业的长久稳定发展。

在实际作业中, 种植人员先要深化 自身的责任意识, 了解规模化发展要点, 参照现有条件和资源, 逐步完善和落实 标准化管理方案, 并加大机械设备的使 用率, 落实机械化生产要求, 以实现烟草 的规模化、批量化生产, 保证烟草质量。 而针对实力较强的种植户, 则可通过与 生产合作社的协同作业, 扩大烟草种植 规模, 引进先进技术和设备, 做到对烟草 种植过程的科学监督和管控, 改进烟草 质量, 抵御外界不良环境的侵袭。在大户
经营的基础上, 探索利用土地资源丰富、 地势平坦、开阔、适于机械化作业的地 方, 积极引导发展烟叶生产专业村、规模 种植专业乡镇、特色优势产业带, 培育规 模化种烟模式, 尝试走出一条极具特色 的规模化、专业化种植道路。

2.4 提高信息化水平, 加强技术服务

企业需加大基层站点中信息技术的 应用力度, 构建完善的信息化处理平台, 做好信息数据收集和实时更新, 且及时 了解烟草生产情况和市场需求, 调整生 产方案。另外, 在信息技术支持下, 了解 客户需求, 为其提供更多专业的高质量 的服务活动, 加大合作力度, 从而维护双 方的经济效益, 推动行业的健康发展。

\section{5 构建专业的烟农队伍}

烟农是提升基础生产水平的关键, 是改进烟草质量、推动烟草农业稳定长 久发展的根本, 只有不断完善烟农自身 的能力素质, 才能为烟草农业发展带来 新的生机和希望。为此, 在现今烟草农 业发展中, 应构建专业性较强的烟农队 伍, 推动基础烟草的专业性、标准化、 高效化生产。培育出懂技术、善经营、 会管理的新型烟农队伍, 使所有先进的 管理理念、技术水平、基础设施都能在 此基础上充分地发挥效用, 这样烟叶产 业才能真正做到良性循环, 有效改善烟 叶水平, 真正达到烟农增收、企业增效 的目的。

\section{3 基础烟草生产管理体系组织}

\section{机构的优化}

3. 1完善烟站管理体系

在现有的烟站管理体系中, 做好内 部管理关系的明确及职能的科学划分, 可实现对区域内基础烟草生产的管理和 控制, 避免因管理区域划分不明、管理工 作重复开展带来的各类问题, 优化基础 烟草生产管理水平, 规范基础作业人员
的行为, 从而提高烟草质量和产量, 维护 烟农的经济效益, 调动烟农种植及生产 的积极性。借助烟叶生产管理的信息化 建设, 有力督促基层业务人员按时, 按量, 按规范开展基层服务工作, 同时利用信 息化将烟叶生产政策, 生产培训, 生产技 术有效的落实在烟农身上, 增大烟农的 应得利益, 调动烟民种植的积极性。

3. 2 创新烟草生产管理模式, 实现资 源整合, 提高管理水平

创新生产管理模式, 可剔除传统管 理模式中存在的弊端, 对现有资源加以 整合和优化, 从而改进基础烟草的生产 质量, 提升管理水平。同时还可降低管理 中成本的损耗, 构建节约型产业结构。管 理模式的创新离不开先进技术的合理应 用, 借助信息技术、大数据技术等, 构建 完善的信息处理平台, 可及时了解烟草 种植和生产的具体情况, 及时解决出现 问题, 加大监管力度, 以促进各项工作的 顺利开展, 减少不必要浪费或损耗的产 生, 增大烟草企业的经济效益。

\section{4 结语}

综上所述, 基层烟草生产管理水平 的提高, 生产作业流程的规划, 可加强基 础烟草的规范化、机械化作业效果, 进而 改善烟草生产质量, 促进整个行业的持 续前行, 丰富社会经济架构。

\section{[参考文献]}

[1] 蒋海洋,朱天义,吉贵锋,等.基层 烟叶生产管理存在的问题及对策[J].现 代农业科技,2018(02):43+46.

[2]何小亚.新形势下加强遵义烟草 基层烟叶队伍建设的思考 [J]. 法制博 览,2017(20):211.

[3]蔡赫.基础烟叶生产中存在 的问题及应对措施 [J]. 科技创新与应 用,2015(29):140. 